\title{
Review Article \\ Hydrogen Sulfide Signaling Axis as a Target for Prostate Cancer Therapeutics
}

\author{
Mingzhe Liu, ${ }^{1}$ Lingyun Wu, ${ }^{1,2}$ Sabine Montaut, ${ }^{3}$ and Guangdong Yang ${ }^{3}$ \\ ${ }^{1}$ Cardiovascular and Metabolic Research Unit, Lakehead University, Thunder Bay, ON, Canada P7B 5E1 \\ ${ }^{2}$ Department of Health Sciences, Lakehead University, Thunder Bay, ON, Canada P7B 5E1 \\ ${ }^{3}$ Department of Chemistry and Biochemistry, Laurentian University, Sudbury, ON, Canada P3E 2C6
}

Correspondence should be addressed to Guangdong Yang; gyang2@laurentian.ca

Received 19 October 2015; Accepted 28 January 2016

Academic Editor: David Nanus

Copyright (C) 2016 Mingzhe Liu et al. This is an open access article distributed under the Creative Commons Attribution License, which permits unrestricted use, distribution, and reproduction in any medium, provided the original work is properly cited.

\begin{abstract}
Hydrogen sulfide $\left(\mathrm{H}_{2} \mathrm{~S}\right)$ was originally considered toxic at elevated levels; however just in the past decade $\mathrm{H}_{2} \mathrm{~S}$ has been proposed to be an important gasotransmitter with various physiological and pathophysiological roles in the body. $\mathrm{H}_{2} \mathrm{~S}$ can be generated endogenously from L-cysteine by multiple enzymes, including cystathionine gamma-lyase, cystathionine beta-synthase, and 3mercaptopyruvate sulfurtransferase in combination with cysteine aminotransferase. Prostate cancer is a major health concern and no effective treatment for prostate cancers is available. $\mathrm{H}_{2} \mathrm{~S}$ has been shown to inhibit cell survival of androgen-independent, androgen-dependent, and antiandrogen-resistant prostate cancer cells through different mechanisms. Various $\mathrm{H}_{2} \mathrm{~S}$-releasing compounds, including sulfide salts, diallyl disulfide, diallyl trisulfide, sulforaphane, and other polysulfides, also have been shown to inhibit prostate cancer growth and metastasis. The expression of $\mathrm{H}_{2} \mathrm{~S}$-producing enzyme was reduced in both human prostate cancer tissues and prostate cancer cells. Androgen receptor (AR) signaling is indispensable for the development of castration resistant prostate cancer, and $\mathrm{H}_{2} \mathrm{~S}$ was shown to inhibit AR transactivation and contributes to antiandrogen-resistant status. In this review, we summarized the current knowledge of $\mathrm{H}_{2} \mathrm{~S}$ signaling in prostate cancer and described the molecular alterations, which may bring this gasotransmitter into the clinic in the near future for developing novel pharmacological and therapeutic interventions for prostate cancer.
\end{abstract}

\section{Introduction}

Hydrogen sulfide $\left(\mathrm{H}_{2} \mathrm{~S}\right)$ is a colorless, flammable gas with the characteristic odor of rotten eggs. $\mathrm{H}_{2} \mathrm{~S}$ is traditionally considered as a toxic environmental pollutant with little or no physiological significance. The mechanism of $\mathrm{H}_{2} \mathrm{~S}$ toxicity is thought to bind and inhibit mitochondrial cytochrome $c$ oxidase, which is involved in cellular oxidative processes and energy production [1]. The inhibition of cytochrome $c$ oxidase blocks the electron transport chain, decreases ATP production, and finally induces cell death. However, just in the last decade, $\mathrm{H}_{2} \mathrm{~S}$ is acknowledged to be one important gasotransmitter, influencing plentiful physiological and pathological processes [2-6]. In 1998, three Nobel winners in Medicine and Physiology, Drs. Robert F. Furchgott, Louis J. Ignarro, and Ferid Murad, discovered that nitric oxide (NO) is an endothelial-derived relaxing factor and acts as a signaling molecule in the cardiovascular system. We now know that $\mathrm{NO}$ is the first identified gasotransmitter. Similar to NO, $\mathrm{H}_{2} \mathrm{~S}$ possesses all the criteria to qualify as a gasotransmitter $[4,6]$. First, $\mathrm{H}_{2} \mathrm{~S}$ is a small gas with the simple molecular structure of two hydrogen atoms and one sulfide atom. Secondly, $\mathrm{H}_{2} \mathrm{~S}$ has higher lipid solubility and can penetrate easily through cell membranes without using any specific transporter/receptor. Thirdly, $\mathrm{H}_{2} \mathrm{~S}$ not only is found from the environment, but also can be endogenously generated in almost all organs and cells by specific enzymes through reverse-transsulfuration pathway. Fourthly, $\mathrm{H}_{2} \mathrm{~S}$ generates various functions at physiologically relevant concentrations by targeting at specific cellular and molecular sites, which can be mimicked by exogenously applied $\mathrm{H}_{2} \mathrm{~S}$ donors. 


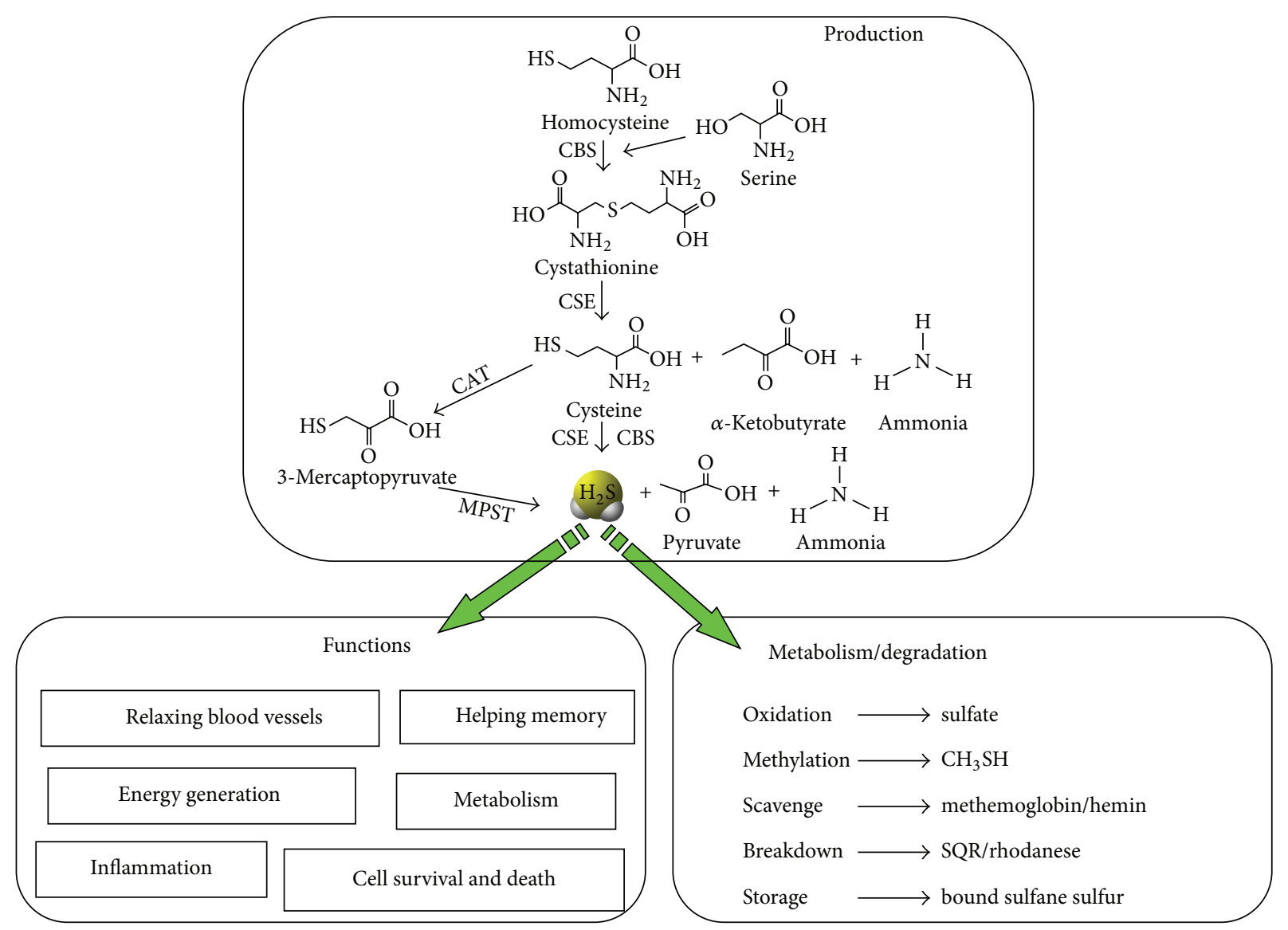

FIGURE 1: $\mathrm{H}_{2} \mathrm{~S}$ biosynthesis, functions, and metabolism. So let us first look at how $\mathrm{H}_{2} \mathrm{~S}$ is endogenously produced. In mammalian cells, $\mathrm{H}_{2} \mathrm{~S}$ can be endogenously produced through the transsulfuration pathway. With cysteine as the main substrate, CBS or CSE, which we called cystathionine gamma-lyase or cystathionine beta-synthase, can catalyze cysteine into $\mathrm{H}_{2} \mathrm{~S}$ and other products. The expression of CBS and CSE is tissue-specific, CBS is mostly expressed in brain, and CSE is in the cardiovascular system and other big tissues, such as liver and kidney. The half-life of $\mathrm{H}_{2} \mathrm{~S}$ inside the cells is very fast; it is estimated in several seconds and can be quickly oxidized, scavenged, or broken down by different ways. Now it has been widely recognized that $\mathrm{H}_{2} \mathrm{~S}$ plays very important physiological role in the whole body and also cells; for example, it can relax blood vessel and acts as an endothelial deprived hyperpolarizing factor, can enhance long term potentiation and help memory, and can control energy generation and regulate metabolism, inflammation; more importantly, $\mathrm{H}_{2} \mathrm{~S}$ is required for cell fate decision; that is the topic we are going to talk about in the following.

$\mathrm{H}_{2} \mathrm{~S}$ is involved in an array of cellular signals regulating cardiac, neurological, and respiratory functions, as well as cellular metabolism and survival [5, 7]. Many diseases including cardiovascular diseases, neurological diseases, shock, sepsis, metabolic disorders, and cancers have been linked to abnormal endogenous $\mathrm{H}_{2} \mathrm{~S}$ functions and metabolism [4]. Although $\mathrm{H}_{2} \mathrm{~S}$ has numerous physiological functions, the actual levels of $\mathrm{H}_{2} \mathrm{~S}$ present in biological tissues and fluids are not really known. The past studies have shown that the concentration of $\mathrm{H}_{2} \mathrm{~S}$ in circulation ranged from nanomolar to micromolar one depending on different detection methods [2]. $\mathrm{H}_{2} \mathrm{~S}$ usually provides cytoprotective effects at very low concentrations but is cytotoxic at higher concentrations via free radical and oxidant generation, glutathione (GSH) depletion, and initiation of proapoptotic gene expression [8]. It is proposed that $\mathrm{H}_{2} \mathrm{~S}$ mediates all these cellular functions through protein posttranslational modifications. $\mathrm{H}_{2} \mathrm{~S}$ can modify cysteine residues of the proteins and bind with the sulfhydryl group of cysteine forming persulhydral group (-SSH), termed as protein $S$-sulfhydration [9-13]. It is predicted that $S$-sulfhydration changes protein structure and alters protein activity and functions. The modified cysteine residue is highly reactive and usually increases the catalytic activity of targeted proteins [14].

\section{2. $\mathrm{H}_{2} \mathrm{~S}$ Biosynthesis and Metabolism}

Now it is recognized that endogenous $\mathrm{H}_{2} \mathrm{~S}$ generation is from enzymatic and nonenzymatic pathways $[4,5]$. At least 3 enzymes are responsible for endogenous $\mathrm{H}_{2} \mathrm{~S}$ generation in mammalian cells, including two cytosolic pyridoxal- $5^{\prime}$ phosphate-dependent enzymes, cystathionine beta-synthase (CBS, EC 4.2.1.22) and cystathionine gamma-lyase (CSE, EC 4.4.1.1), and a mitochondrial enzyme 3-mercaptopyruvate sulfurtransferase (MPST, EC 2.8.1.2) (Figure 1) [5, 8]. All these three enzymes use sulfur-containing amino acids L-cysteine 
as substrate to generate $\mathrm{H}_{2} \mathrm{~S}$. CBS catalyzes the condensation of serine and homocysteine to form cystathionine, and CSE then cleaves the $C-\gamma$-S bond of cystathionine to yield cysteine, $\alpha$-ketobutyrate, and ammonia $\left(\mathrm{NH}_{3}\right)$. Moreover, both CBS and CSE can use cysteine as substrate to produce $\mathrm{H}_{2} \mathrm{~S}$, and pyruvate and $\mathrm{NH}_{3}$ are two other byproducts. Cysteine aminotransferase (CAT) provides 3-mercaptopyruvate from cysteine for MPST to produce $\mathrm{H}_{2} \mathrm{~S}$. These enzymes are critical for the maintenance of $\mathrm{H}_{2} \mathrm{~S}$ homeostasis by precisely regulating $\mathrm{H}_{2} \mathrm{~S}$ levels in tissues [8]. It is worth noting that MPST functions more efficiently at very high $\mathrm{pH}$. At physiological condition, the contribution of MPST to endogenous $\mathrm{H}_{2} \mathrm{~S}$ production is negligible in comparison with CBS and CSE [15]. The expression of these 3 enzymes in the body is tissuespecific. They can be all expressed in one organ, or only one of them is expressed in the specific organ. In cardiovascular system, CSE probably is the major $\mathrm{H}_{2} \mathrm{~S}$-producing gene, helps vascular tone, and regulates blood pressure. In the brain and peripheral nervous system, CBS and MPST are the major $\mathrm{H}_{2} \mathrm{~S}$-producing enzymes, help brain for neuromodulation, and stimulate memory. In pancreas, both CBS and CSE can be expressed, but only CSE acts as the critical enzyme to produce $\mathrm{H}_{2} \mathrm{~S}$, regulating insulin release and cell survival of insulin-secreting beta cells. In lungs, so far only CBS and CSE are showed to be expressed, and $\mathrm{H}_{2} \mathrm{~S}$ regulates airway contraction and delays asthma development. In intestine, $\mathrm{H}_{2} \mathrm{~S}$ is of bacterial origin or also is produced from both CBS and CSE, helping inflammation and pain. In the large organ, for example, liver and kidney, all three enzymes are expressed, and $\mathrm{H}_{2} \mathrm{~S}$ can be vastly produced by these two tissues $[2,3]$.

$\mathrm{H}_{2} \mathrm{~S}$ can also be produced endogenously through nonenzymatic pathways and elemental sulfur, including thiosulfate, thiocysteine, and other molecules in the blood, which can be reduced to $\mathrm{H}_{2} \mathrm{~S}$ through the glycolytic pathway (Figure 1) [5]. Another important source of $\mathrm{H}_{2} \mathrm{~S}$ is from the $\mathrm{H}_{2} \mathrm{~S}$ producing bacteria existing in the intestinal system. The concentration of $\mathrm{H}_{2} \mathrm{~S}$ inside the cells is accurately regulated to maintain the proper physiological function of $\mathrm{H}_{2} \mathrm{~S}$ [7]. $\mathrm{H}_{2} \mathrm{~S}$ can be quickly and spontaneously oxidized to thiosulfate and then to sulfite or sulfate in the presence of oxygen and $\mathrm{Fe}^{3+}$ iron in mitochondria. Recent reports showed that $\mathrm{H}_{2} \mathrm{~S}$ also can be oxidized to polysulfides $\left(\mathrm{H}_{2} \mathrm{Sn}\right)$, which are thought to be more stable than $\mathrm{H}_{2} \mathrm{~S}$ and act as more potent signaling molecules [8]. In cytosol, $\mathrm{H}_{2} \mathrm{~S}$ interacts with various proteins in the blood, including metalloproteins, disulfidecontaining proteins, and thio-S-methyltransferase, forming methyl sulfides, while methylation of $\mathrm{H}_{2} \mathrm{~S}$ is much slower than mitochondrial oxidation [5].

\section{Expression of $\mathrm{H}_{2} \mathrm{~S}$-Generating Enzymes in Prostate Tissues}

In 2012, Guo et al. thoroughly analyzed the expressions of $\mathrm{H}_{2} \mathrm{~S}$-generating genes in human prostatic tissue (epithelial and stroma cells) and different prostatic normal, benign, and cancer cell lines [16]. The prostatic tissue stromal compartments and stroma cell WPMY-1 presented middle to strong signals of CSE. The protein levels of CBS and CSE are greatest in the androgen-dependent prostate cancer cell
LNCaP in comparison with all other cells. In LNCaP cells, both CBS and CSE are located in the cytoplasm as evidenced by immunostaining, and the CBS/CSE activities parallel the CBS/CSE protein levels [16]. In contrast, CBS and CSE are hardly detected in the normal prostatic peripheral zone epithelial cell line RWPE-1. Gai et al. further demonstrated that not only CBS and CSE but also MPST is present in human prostate tissue, and CSE is expressed at much higher level in comparison with CBS and MPST [17]. In contrast, Zhao et al. found that MPST is not expressed in both human prostate adenocarcinoma and normal prostate tissues [18]. The difference may be due to the detection method and antibody resource. Furthermore, Zhao et al. provided evidence that the expression of CSE but not CBS is significantly reduced in prostate cancer tissue when compared with normal prostate tissues [18]. CSE expression is also lower in antiandrogen-resistant prostate cancer cells in comparison with their parental LNCaP cells, whereas the expression of CBS is similar between these two types of cells. Pei et al. confirmed that both CSE and CBS are expressed in mouse prostate tissues, in both androgen-dependent and androgenindependent prostate cancer cells (LNCaP and PC-3) [19]. Both CBS and CSE use cysteine as substrate to produce $\mathrm{H}_{2} \mathrm{~S}$; however the contribution of CBS and CSE to $\mathrm{H}_{2} \mathrm{~S}$ production in prostate tissue is quite different. Complete removal of CSE gene in mice eliminated $\mathrm{H}_{2} \mathrm{~S}$ production by more than $80 \%$ in prostate tissues in comparison with that from wild-type mice, indicating that CSE but not CBS acts as a major $\mathrm{H}_{2} \mathrm{~S}$ producing enzyme in prostate.

\section{Altered Sulfide Metabolism in Patients with Prostate Cancer}

Prostate cancer is the most invasive and frequently occurring cancer among men with nearly a million new cases diagnosed worldwide annually [20]. Prostate cancer has approximately a sixfold higher incidence in Western than in nonWestern countries. Prostate cancer arises from malignant transformation of prostate cells, and prostate cancer cells have the potential for invasion of neighboring organs and form metastases mostly in lymph nodes and bone [21]. Androgen ablation therapy and radical prostatectomy are the main treatment options for early stage prostate cancer. However in the final stage prostate cancer progresses to a castration resistant state that is highly aggressive, metastatic, and resistant to chemotherapy and finally causes the death of patient, which accounts for approximately 30,000 deaths in the US in 2014 [22]. Development of novel diagnosis and preventive interventions are urgent to reduce morbidity, mortality, and healthcare cost associated with this tumor. New markers of this aggressive disease are also critically needed for clinical decision.

Several lines of evidence recently demonstrated that altered sulfide metabolism is involved in patients with prostate cancer [23-25]. Mitochondria can oxidize $\mathrm{H}_{2} \mathrm{~S}$ to thiosulfate and then to sulfite, which is excreted by the kidney in urine, so thiosulfate is a naturally occurring metabolic product from $\mathrm{H}_{2} \mathrm{~S}$. The concentration of thiosulfate will be increased in urine when people are exposed to 
$\mathrm{H}_{2} \mathrm{~S}$ or if $\mathrm{H}_{2} \mathrm{~S}$ metabolism is disrupted inside the body. Chwatko et al. recently compared the thiosulfate level in the urine samples from 166 prostate cancer patients, 42 benign prostatic hyperplasia cases, and 20 healthy people [26]. Interestingly, they found that the urinal thiosulfate level in prostate cancer patients is almost 50 times higher than in the control groups and 5 times higher than in the benign prostatic hyperplasia group, suggesting an impaired $\mathrm{H}_{2} \mathrm{~S}$ metabolism in prostate cancer. Furthermore, Chwatko et al. observed that the level of thiosulfate is positively related with prostate tumor volume but not tumor stage and grade [26]. It is paradoxical that the level of thiosulfate does not correlate with serum prostate-specific antigen (PSA) level. It is not clear how thiosulfate level is higher in the urine samples from prostate cancer patients. Several enzymes, including thiosulfate/cyanide sulfur transferase (TST, rhodanese) and sulfite oxidase, are involved in $\mathrm{H}_{2} \mathrm{~S}$ oxidation to thiosulfate [5]. Further analysis on the change of these enzymes will provide more clues on the altered thiosulfate level in prostate cancer.

In addition, Kimura et al. observed that the products of methionine catabolism are correlated with prostate cancer progression status [27]. Cysteine, the substrate required for all 3 enzymes to generate $\mathrm{H}_{2} \mathrm{~S}$, is significantly elevated in the urine samples from biochemically recurrent prostate cancer patients compared to those who remained recurrencefree five years following prostatectomy. Along with cysteine, homocysteine and cystathionine are also significantly higher in the biochemically recurrent patients, suggesting that cysteine, cystathionine, and homocysteine can act as independent predictors of recurrence-free survival for prostate cancer patients. In contrast, the concentration of cysteine is reported to be significantly lower in plasma as a result of prostate tumor progression in nude mice implanted with human prostate cancer cells $[28,29]$. Further studies need to be clarified on the altered sulfide metabolism in patients with prostate cancer.

Multiple studies also showed that the other products from sulfide amino acid metabolism are higher in prostate cancer patient. Sarcosine ( $N$-methylglycine), a product of methionine catabolism, is reported to be higher in the urine of patients with metastatic prostate disease and is also higher in tissues from localized prostate cancer than in normal tissue [30]. Therefore, urinary sarcosine can also be used as a possible marker for metastatic prostate cancer.

\section{5. $\mathrm{H}_{2} \mathrm{~S}$ Inhibition of Prostate Cancer Cell Growth}

The functional importance of $\mathrm{H}_{2} \mathrm{~S}$ in the biology of the prostate cancer cells is recently recognized [31, 32]. Epidemiological, clinical, and laboratory studies have shown that $\mathrm{H}_{2} \mathrm{~S}$ and/or sulfide-containing compounds inhibit the survival of prostate cancer cells in vitro and in vivo (Figure 2). An increased intake of garlic and cruciferous vegetables has long been associated with a reduced risk in the occurrence and progression of prostate cancer [33-35]. Garlic contains different sulfur-containing compounds (Figure 2), including diallyl disulfide (DADS), diallyl trisulfide (DATS), allicin, and allyl-methyl-thiosulfinate, which are useful organic sources of $\mathrm{H}_{2} \mathrm{~S}$ via reactions involving alliinase-mediated enzymatic conversion of $S$-alk(en)yl-L-cysteine sulfoxide to alkyl alkane thiosulfinates, followed by instant decomposition of these byproducts [36-39]. Benavides et al. also reported that garlic sulfur-containing compounds are able to release $\mathrm{H}_{2} \mathrm{~S}$ with a relatively slow mechanism in the presence of endogenous thiols, such as GSH [40]. In addition, Bhuiyan et al. provided evidence showing that TST catalyzes garlic extracts to release $\mathrm{H}_{2} \mathrm{~S}$ in vitro in the presence of reduced thioredoxin [36]. Cruciferous vegetables uniquely contain a group of sulfurcontaining compounds known as isothiocyanates, which can release $\mathrm{H}_{2} \mathrm{~S}$ under specific conditions. Sulforaphane (SFN) (Figure 2) is one of the principle isothiocyanates which prevents or delays tumor development in a variety of animal models of prostate cancers [41, 42].

5.1. Sulfide Salts. NaHS is a well-used $\mathrm{H}_{2} \mathrm{~S}$ donor, which can cause rapid $\mathrm{H}_{2} \mathrm{~S}$ release (Figure 2). In physiological saline, $\mathrm{NaHS}$ dissociates into $\mathrm{Na}^{+}$and $\mathrm{HS}^{-}$, and then $\mathrm{HS}^{-}$associates with $\mathrm{H}^{+}$to form $\mathrm{H}_{2} \mathrm{~S}$, and about one-third of the $\mathrm{H}_{2} \mathrm{~S}$ exists in the undissociated form. Pei et al. first observed that NaHS at $50-200 \mu \mathrm{M}$ significantly decreases cell viability of PC3 cells, an androgen-unresponsive metastatic cell line [19]. Blockage of the phosphorylation of both p38 MAPK and JNK reversed the inhibitory effects of NaHS on PC-3 cell viability. By using the same cell line, CSE overexpression enhanced $\mathrm{H}_{2} \mathrm{~S}$ production and inhibited cell viability in PC-3 cells. This occurred also in androgen-independent prostate cancer cell line. Exogenously applied NaHS at $30 \mu \mathrm{M}$ significantly suppressed cell viability in both androgen responsive cells and antiandrogen-resistant cells in the presence or absence of R1881 [11]. Remarkably, in comparison with young mice, CSE expression and $\mathrm{H}_{2} \mathrm{~S}$ production in prostate tissue from older mice were significantly reduced, accompanied by an increased cell proliferation evidenced by an increased expression of PCNA and cyclin D1. The authors indicated that $\mathrm{CSE} / \mathrm{H}_{2} \mathrm{~S}$ system may be essential for maintaining the balance of age-linked cell growth in prostate tissues.

In addition, Duan et al. investigated the inhibitory effects of sulfur on prostate tumor growth in vivo [43]. The nude mice were inoculated with prostate cancer cells (22Rvl and DU145) following feeding with $0.62 \mathrm{~g} /$ day sulfur-milk powder for 22 days, while the control mice inoculated with prostate cancer cells were only provided with milk powder. Serum $\mathrm{H}_{2} \mathrm{~S}$ level in the sulfur-treated mice was significantly increased. The rate of growth of tumors in sulfur-treated mice was markedly reduced when compared with that of the control group. The prostate cancer cells separated from the sulfurtreated xenograft tumors formed much lower clones than that of the control tumors, indicating that the clonogenicity of $22 \mathrm{Rv} 1$ or DU-145 prostate cancer cells is significantly decreased by sulfur. Interestingly, as early as forty years ago, clinical practice had showed that treatment with $\mathrm{H}_{2} \mathrm{~S}$ water improves blood supply to the prostate gland in patients with chronic prostatitis, pointing to the beneficial role of $\mathrm{H}_{2} \mathrm{~S}$ in prostate tissue under pathological condition [44].

5.2. DADS. DADS (Figure 2) is one of the principal organosulfur compounds from garlic and a few other Allium 


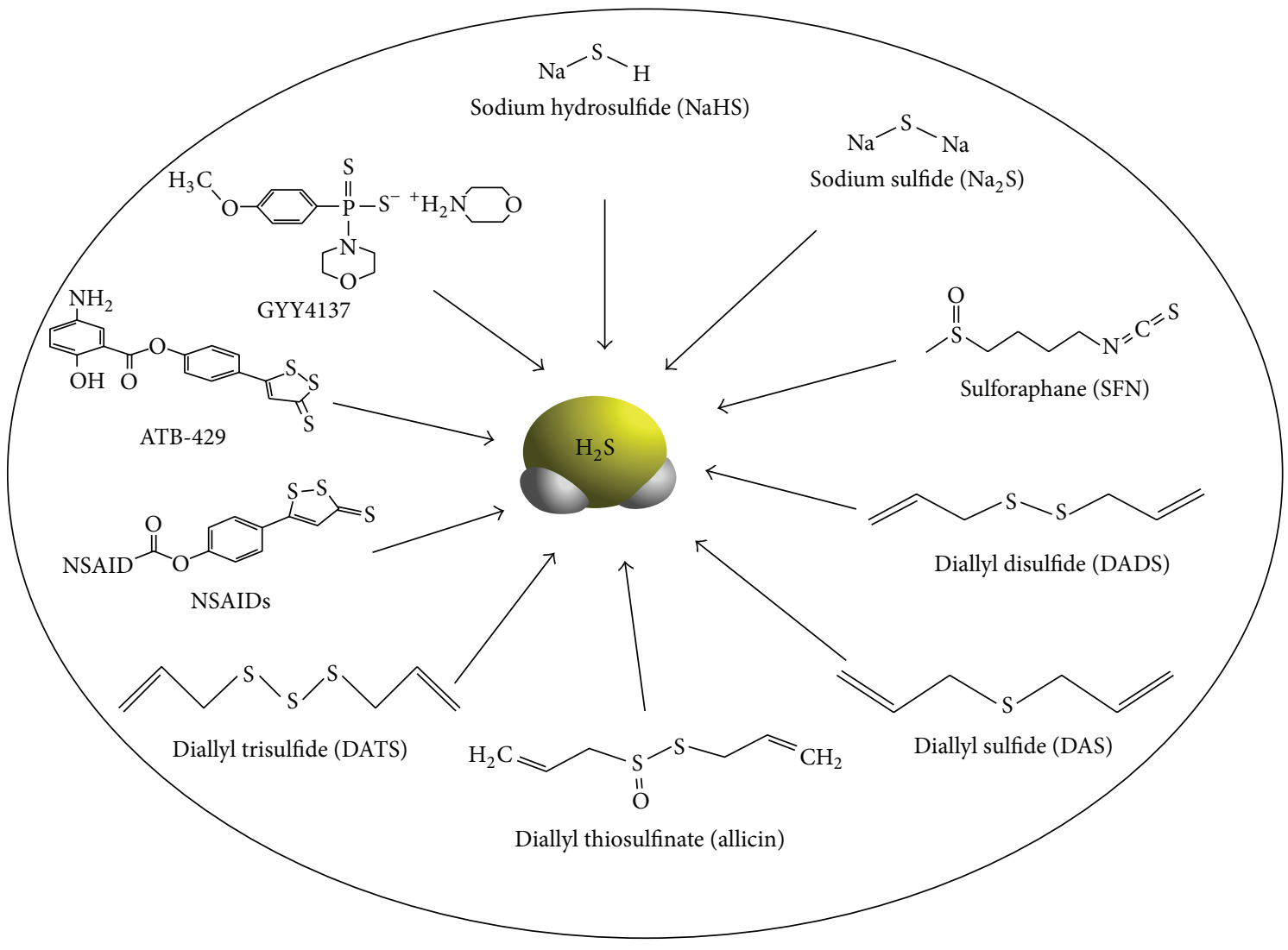

FIGURE 2: $\mathrm{H}_{2} \mathrm{~S}$-releasing donors.

plants $[45,46]$. Arunkumar et al. proved that DADS at $10-50 \mu \mathrm{M}$ inhibits cell survival and induces cell apoptosis of androgen-independent prostate cancer cells (PC-3) in a dose-dependent manner $[47,48]$. DADS was found to downregulate the expression of insulin-like growth factor signaling system, which subsequently leads to inhibition of Akt phosphorylation and the expressions of cyclin D1, NF $\kappa \mathrm{B}$, and antiapoptotic $\mathrm{Bcl}-2$ protein, but increases proapoptotic signaling proteins (Bad and Bax), thereby inhibiting cell cycle progression and survival. The same group further demonstrated that DADS provides chemopreventive activity in rat prostate carcinogenesis [49], which was induced by injecting the rats with testosterone and $N$-methyl $N$ nitrosourea (MNU) throughout the experimental period.

Chen et al. found that DADS induces cell death in PC-3 cells by stimulating $\mathrm{Ca}^{2+}$ release from endoplasmic reticulum in a phospholipase $\mathrm{C}$-independent manner and also causing $\mathrm{Ca}^{2+}$ influx via phospholipase A2-dependent manner [50]. Many other studies also confirmed that DADS suppressed the proliferation of prostate cancer cells through cell cycle arrest and apoptosis [51-53]. It is clear that DADS may be used for further drug discovery approach in the prostate cancer therapy.

5.3. DATS. Similar to DADS, DATS (Figure 2) is also a natural product with a pungent odor and volatility when isolated from garlic and has been shown to have anti-prostate cancer activity both in vitro and in vivo [54-58]. DATS significantly induces cell death of prostate cancer cells (PC-3) but not of noncancerous human prostate epithelial PNT1A cells. DATS stimulated more ROS formation, ferritin degradation, inactivation of Akt, and activation of ERK1/2 in PC-3 cells in comparison with PNT1A cells, which may explain the higher sensitivity of prostate cancer cells to the cytotoxic effects of DATS $[54,59]$. Sielicka-Dudzin et al. showed that DATS induces cell death of prostate cancer cells (PC3) via JNK1-dependent ROS formation and Itch-dependent ferritin degradation, while DATS-induced cell cycle arrest in DU145 cells is associated with delayed nuclear translocation of cyclin-dependent kinase $1[60,61]$. Chen et al. further confirmed that DATS and its derivatives, including dibutenyl trisulfide (DBTS), bis(2-methylallyl) trisulfide (2-M-DATS), dipentenyl trisulfide (DPTS), bis(3-methylbut-2-enyl) trisulfide (3-M-DBTS), and dihexenyl trisulfide (DHTS), induce cell apoptosis of PC-3 cells in a dose- and time-dependent manner through increasing the $\mathrm{Bax} / \mathrm{Bcl}-2$ ratio and activation of procaspase-3 [62].

Administration of DATS also significantly inhibits the progression of prostate carcinoma in transgenic adenocarcinoma of mouse prostate (TRAMP) mice and reduces the growth of PC-3 xenografts in athymic mice $[63,64]$. The TRAMP mice are a well-known model for studying human prostate cancer, because they share many features important in human prostate cancer progression, including metastasis 
to distant sites, progression to androgen independence, and neuroendocrine differentiation [63]. Kim et al. also observed that the incidence of poorly differentiated prostate cancer is reduced by about $34-41 \%$ in the dorsolateral prostate of DATS-treated TRAMP mice in comparison with controls [59]. In another mouse model, DATS induces apoptosis and inhibits tumor cell proliferation, metastasis, and angiogenesis in BALB/c nude mice orthotopically transplanted with PC-3 prostate carcinoma compared with the control group [65].

5.4. SFN. SFN (Figure 2), a major isothiocyanate, is especially abundant in broccoli and broccoli sprouts. SFN has been widely demonstrated to induce prostate cancer cell apoptosis and reduce the growth of prostate cancer in animal models $[66,67] . \mathrm{H}_{2} \mathrm{~S}$ is able to mediate the antiproliferative role of SFN on prostate cancer cells through the activation of p38 mitogen-activated protein kinases (MAPK) and c-Jun N-terminal kinase (JNK) [19]. We previously observed that SFN acts as a slow-releasing $\mathrm{H}_{2} \mathrm{~S}$ donor supported by several findings. Firstly, when SFN was added into cell culture medium with PC-3 cells, the concentration of $\mathrm{H}_{2} \mathrm{~S}$ was doubled and lasted for at least 4 hours. Secondly, SFN released more $\mathrm{H}_{2} \mathrm{~S}$ in the presence of liver homogenate, suggesting that SFN may liberate $\mathrm{H}_{2} \mathrm{~S}$ under specific condition. SFN reacts with glutathione (GSH) to form a GSH conjugate in the mercapturic acid pathway, so it is highly possible that the existence of PC-3 cells or liver homogenates may provide enzymes to facilitate SFN binding with $\mathrm{GSH}$ for $\mathrm{H}_{2} \mathrm{~S}$ liberation. Thirdly, halting of $\mathrm{H}_{2} \mathrm{~S}$ production by methemoglobin or oxidized glutathione (two $\mathrm{H}_{2} \mathrm{~S}$ scavengers) abolished SFNstimulated MAPK activities and reversed the inhibitory role of SFN on PC-3 growth. Although SFN is well known to suppress prostate cancer in various animal models, recent phase II study reported that the treatment of prostate cancer patients with SFN-rich broccoli sprout extracts did not affect PSA level [68]. Further studies with higher doses of SFN-rich broccoli sprout extracts may be warranted to clarify the role of SFN as a prevention agent for prostate cancer.

\section{6. $\mathrm{H}_{2} \mathrm{~S}$ Interaction with Androgen Receptor}

Androgen is essential for normal prostate physiology and plays a key role in either the initiation or progression of prostate cancer [69]. Androgen receptors (AR) can be activated by androgenic hormones and regulate the development of prostate cancer, as well as its transition to castration resistance state, and continued reliance on AR signaling is a hallmark of prostate cancer progression. The development of potential cancer chemopreventive and therapeutic agents to suppress AR signaling is highly desirable for clinical treatment on prostate cancer. Zhao et al. recently found that $\mathrm{H}_{2} \mathrm{~S}$ suppresses AR transactivation but had no effect on AR protection expression, as evidenced by decreased AR binding with androgen responsive element (ARE) present in the promoter region of $\mathrm{AR}$ target genes. In addition, $\mathrm{H}_{2} \mathrm{~S}$ lowers ARE luciferase activity [18]. Further studies demonstrated that $\mathrm{H}_{2} \mathrm{~S}$ posttranslationally modifies AR proteins through $S$-sulfhydration. Both cysteine-611 and cysteine-614 present in the second zinc finger motif of DNA binding domain
(DBD) are the target for $\mathrm{H}_{2} \mathrm{~S} S$-sulfhydration or AR protein, because mutation of these two cysteine residues completely abrogated $S$-sulfhydration of AR and AR dimer formation. It is predicted that the interaction of $\mathrm{H}_{2} \mathrm{~S}$ with both cysteine-611 and cysteine-614 in AR-DBD alters local structure and leads to abnormal AR dimerization and DNA binding ability.

Another study showed that sulfide feeding of nude mice inoculated with human prostate cancer cells significantly decreases the expression of AR and its downstream genes PSA and NKX3.1, indicating that downregulation of the AR signaling pathway contributed to the inhibitory effects of sulfur on prostate cancer growth [43]. DATS is also shown to suppress AR function in prostate cancer cells. DATS incubation with prostate cancer cells (LNCaP, C42, and TRAMP-C1) decreases the protein expression of AR following the suppression of intracellular and secreted levels of PSA. Further studies showed that oligosulfide derived from DATS decreases AR promoter activity and AR mRNA level. DATS treatment inhibited synthetic androgen- (R1881-) stimulated nuclear translocation of AR in LNCaP/C4-2 cells. Interestingly, DATS treatment also caused a concentrationdependent decrease in phosphorylation of AR in LNCaP and C4-2 cells. In vivo data showed that oral gavage of DATS to TRAMP mice markedly inhibited AR protein level [70]. In contrast, DATS-mediated decrease in AR protein expression is insignificant in the normal prostate, suggesting DATS is unlikely to interfere with AR function in the normal prostate. Another $\mathrm{H}_{2} \mathrm{~S}$-releasing donor, $\mathrm{SFN}$, also suppressed the expression of AR protein by inhibiting the cytoplasmic protein deacetylase HDAC6 in prostate cancer cells [71, 72].

\section{Prospective}

The realization of and interest in the functional importance of $\mathrm{H}_{2} \mathrm{~S}$ in preventing cancer are growing. Despite the inconsistent and inconclusive findings in the field of $\mathrm{H}_{2} \mathrm{~S}$ research, it appears that there is no doubt in the application of $\mathrm{H}_{2} \mathrm{~S}$ in regulating numerous physiological and pathological conditions. Accurate determination of $\mathrm{H}_{2} \mathrm{~S}$ levels in the circulation and tissues is challenging, but it is indispensable for further analyzing the levels of $\mathrm{H}_{2} \mathrm{~S}$ and its metabolites in prostate cancer patients. Most of $\mathrm{H}_{2} \mathrm{~S}$ donors extensively used in the present studies are of limited therapeutic value, due to the weakness of rapid release, instability, volatility, lack of specificity, and so forth. These limitations damper the enthusiasm for their further use as pharmaceutical drugs. Design and development of safer, controllable, and efficient $\mathrm{H}_{2} \mathrm{~S}$-based drugs to be locally delivered to prostate tissue are highly expected. Deciphering the molecular targets of $\mathrm{H}_{2} \mathrm{~S}$ in prostate cancer progression at different stages will help us move forward to specific therapeutic applications. Despite the involvement of $\mathrm{CSE} / \mathrm{H}_{2} \mathrm{~S}$ system in AR signaling, their interactions in tumor development in both animal models and human prostate cancer patients remain to be elucidated. As more promising discoveries regarding $\mathrm{H}_{2} \mathrm{~S}$ functions in prostate cancer rise to the surface, we expect more translation of the emerging roles of $\mathrm{H}_{2} \mathrm{~S}$ in prostate cancer into human diagnostic and therapeutic approaches to evolve in the near future. 


\section{Abbreviations Used}

AR: Androgen receptor

ARE: Androgen responsive element

CBS: Cystathionine beta-synthase

CSE: Cystathionine gamma-lyase

DADS: Diallyl disulfide

DATS: Diallyl trisulfide

DBD: DNA binding domain

GSH: Glutathione

$\mathrm{H}_{2} \mathrm{~S}$ : Hydrogen sulfide

MPST: 3-Mercaptopyruvate sulfurtransferase

NaHS: Sodium hydrosulfide

$\mathrm{NH}_{3}: \quad$ Ammonia

NO: $\quad$ Nitric oxide

PSA: Prostate-specific antigen

ROS: Reactive oxygen species

SFN: Sulforaphane

TRAMP: Transgenic adenocarcinoma of mouse prostate mice

TST: Thiosulfate: cyanide sulfurtransferase.

\section{Conflict of Interests}

The authors declare that there is no conflict of interests regarding the publication of this paper.

\section{Acknowledgments}

This work was supported by a grant-in-aid from Heart and Stroke Foundation of Canada and a start-up fund from Laurentian University.

\section{References}

[1] K. Ono, T. Akaike, T. Sawa et al., "Redox chemistry and chemical biology of $\mathrm{H}_{2} \mathrm{~S}$, hydropersulfides, and derived species: implications of their possible biological activity and utility," Free Radical Biology and Medicine, vol. 77, pp. 82-94, 2014.

[2] L. Li and P. K. Moore, "An overview of the biological significance of endogenous gases: new roles for old molecules," Biochemical Society Transactions, vol. 35, no. 5, pp. 1138-1141, 2007.

[3] B. Olas, "Hydrogen sulfide in signaling pathways," Clinica Chimica Acta, vol. 439, pp. 212-218, 2015.

[4] R. Wang, "Gasotransmitters: growing pains and joys," Trends in Biochemical Sciences, vol. 39, no. 5, pp. 227-232, 2014.

[5] R. Wang, "Physiological implications of hydrogen sulfide: a whiff exploration that blossomed," Physiological Reviews, vol. 92, no. 2, pp. 791-896, 2012.

[6] R. Wang, "Two's company, three's a crowd: can $\mathrm{H}_{2} \mathrm{~S}$ be the third endogenous gaseous transmitter?" The FASEB Journal, vol. 16, no. 13, pp. 1792-1798, 2002.

[7] J. L. Wallace and R. Wang, "Hydrogen sulfide-based therapeutics: exploiting a unique but ubiquitous gasotransmitter," Nature Reviews Drug Discovery, vol. 14, no. 5, pp. 329-345, 2015.

[8] Y. Zhao, T. D. Biggs, and M. Xian, "Hydrogen sulfide $\left(\mathrm{H}_{2} \mathrm{~S}\right)$ releasing agents: chemistry and biological applications," Chemical Communications, vol. 50, no. 80, pp. 11788-11805, 2014.
[9] A. K. Mustafa, M. M. Gadalla, N. Sen et al., " $\mathrm{H}_{2} \mathrm{~S}$ signals through protein S-sulfhydration," Science Signaling, vol. 2, no. 96, p. ra72, 2009.

[10] A. K. Mustafa, G. Sikka, S. K. Gazi et al., "Hydrogen sulfide as endothelium-derived hyperpolarizing factor sulfhydrates potassium channels," Circulation Research, vol. 109, no. 11, pp. 1259-1268, 2011.

[11] K. Zhao, Y. Ju, S. Li, Z. Altaany, R. Wang, and G. Yang, "Ssulfhydration of MEK1 leads to PARP-1 activation and DNA damage repair," EMBO Reports, vol. 15, no. 7, pp. 792-800, 2014.

[12] G. Yang, K. Zhao, Y. Ju et al., "Hydrogen sulfide protects against cellular senescence via s-sulfhydration of keapl and activation of Nrf2," Antioxidants and Redox Signaling, vol. 18, no. 15, pp. 1906-1919, 2013.

[13] D. Zhang, I. MacInkovic, N. O. Devarie-Baez et al., "Detection of protein S-sulfhydration by a tag-switch technique," Angewandte Chemie-International Edition, vol. 53, no. 2, pp. 575581, 2014

[14] G. Yang, "Protein $S$-sulfhydration as a major sources of $\mathrm{H}_{2} \mathrm{~S}$ bioactivity," Receptors \& Clinical Investigation, vol. 1, no. 4, article e337, 2014.

[15] A. di Masi and P. Ascenzi, " $\mathrm{H}_{2} \mathrm{~S}$ : a 'double face' molecule in health and disease," BioFactors, vol. 39, no. 2, pp. 186-196, 2013.

[16] H. Guo, J.-W. Gai, Y. Wang, H.-F. Jin, J.-B. Du, and J. Jin, "Characterization of hydrogen sulfide and its synthases, cystathionine $\beta$-synthase and cystathionine $\gamma$-lyase, in human prostatic tissue and cells," Urology, vol. 79, no. 2, pp. 483.el-483.e5, 2012.

[17] J.-W. Gai, W. Wahafu, H. Guo et al., "Further evidence of endogenous hydrogen sulphide as a mediator of relaxation in human and rat bladder," Asian Journal of Andrology, vol. 15, no. 5, pp. 692-696, 2013.

[18] K. Zhao, S. Li, L. Wu, C. Lai, and G. Yang, "Hydrogen sulfide represses androgen receptor transactivation by targeting at the second zinc finger module," Journal of Biological Chemistry, vol. 289, no. 30, pp. 20824-20835, 2014.

[19] Y. Pei, B. Wu, Q. Cao, L. Wu, and G. Yang, "Hydrogen sulfide mediates the anti-survival effect of sulforaphane on human prostate cancer cells," Toxicology and Applied Pharmacology, vol. 257, no. 3, pp. 420-428, 2011.

[20] P.-H. Lin, W. Aronson, and S. J. Freedland, "Nutrition, dietary interventions and prostate cancer: the latest evidence," $B M C$ Medicine, vol. 13, article 3, 2015.

[21] E. Stone, "Prostatic intraepithelial neoplasia: will it help doctors pinpoint early prostate cancer?" Journal of the National Cancer Institute, vol. 88, no. 15, pp. 1023-1024, 1996.

[22] L. B. Valenca, C. J. Sweeney, and M. M. Pomerantz, "Sequencing current therapies in the treatment of metastatic prostate cancer," Cancer Treatment Reviews, vol. 41, no. 4, pp. 332-340, 2015.

[23] S. Stabler, T. Koyama, Z. Zhao et al., "Serum methionine metabolites are risk factors for metastatic prostate cancer progression," PLoS ONE, vol. 6, no. 8, Article ID e22486, 2011.

[24] J. I. Toohey, "Sulfur signaling: is the agent sulfide or sulfane?" Analytical Biochemistry, vol. 413, no. 1, pp. 1-7, 2011.

[25] B. A. Vartapetov, N. V. Novikova, and G. M. Trandofilova, "Gonadal dysfunction and the thiol compound metabolism in the testes and prostate," Zhurnal Eksperimental'noi i Klinicheskoi Meditsiny, vol. 17, no. 2, pp. 9-15, 1977.

[26] G. Chwatko, E. Forma, J. Wilkosz et al., "Thiosulfate in urine as a facilitator in the diagnosis of prostate cancer for patients with prostate-specific antigen less or equal $10 \mathrm{ng} / \mathrm{mL}$," Clinical Chemistry and Laboratory Medicine, vol. 51, no. 9, pp. 1825-1831, 2013. 
[27] F. Kimura, K. H. Franke, C. Steinhoff et al., "Methyl group metabolism gene polymorphisms and susceptibility to prostatic carcinoma," Prostate, vol. 45, no. 3, pp. 225-231, 2000.

[28] W. Zhang, A. Braun, Z. Bauman, H. Olteanu, P. Madzelan, and R. Banerjee, "Expression profiling of homocysteine junction enzymes in the NCI60 panel of human cancer cell lines," Cancer Research, vol. 65, no. 4, pp. 1554-1560, 2005.

[29] F. Al-Awadi, M. Yang, Y. Tan, Q. Han, S. Li, and R. M. Hoffman, "Human tumor growth in nude mice is associated with decreased plasma cysteine and homocysteine," Anticancer Research, vol. 28, no. 5, pp. 2541-2544, 2008.

[30] C. Stephan, K. Jung, K. Miller, and B. Ralla, "New biomarkers in serum and urine for detection of prostate cancer," Aktuelle Urologie, vol. 46, no. 2, pp. 129-143, 2015.

[31] M. R. Hellmich, C. Coletta, C. Chao, and C. Szabo, "The therapeutic potential of cystathionine $\beta$-synthetase/hydrogen sulfide inhibition in cancer," Antioxidants and Redox Signaling, vol. 22, no. 5, pp. 424-448, 2015.

[32] K. Kashfi, "Anti-cancer activity of new designer hydrogen sulfide-donating hybrids," Antioxidants and Redox Signaling, vol. 20, no. 5, pp. 831-846, 2014.

[33] S. E. Lupold and R. Rodriguez, "Disulfide-constrained peptides that bind to the extracellular portion of the prostate-specific membrane antigen," Molecular Cancer Therapeutics, vol. 3, no. 5, pp. 597-603, 2004.

[34] S. M. Collin, "Folate and B12 in Prostate Cancer," Advances in Clinical Chemistry, vol. 60, pp. 1-63, 2013.

[35] S. Prasad, N. Kalra, and Y. Shukla, "Modulatory effects of diallyl sulfide against testosterone-induced oxidative stress in Swiss albino mice," Asian Journal of Andrology, vol. 8, no. 6, pp. 719$723,2006$.

[36] A. I. Bhuiyan, V. T. Papajani, M. Paci, and S. Melino, "Glutathione-Garlic sulfur conjugates: slow hydrogen sulfide releasing agents for therapeutic applications," Molecules, vol. 20, no. 1, pp. 1731-1750, 2015.

[37] K. L. Flannigan, T. A. Agbor, J.-P. Motta et al., "Proresolution effects of hydrogen sulfide during colitis are mediated through hypoxia-inducible factor-1 $\alpha$," The FASEB Journal, vol. 29, no. 4, pp. 1591-1602, 2015.

[38] D. Liang, C. Wang, R. Tocmo, H. Wu, L. Deng, and D. Huang, "Hydrogen sulphide $\left(\mathrm{H}_{2} \mathrm{~S}\right)$ releasing capacity of essential oils isolated from organosulphur rich fruits and vegetables," Journal of Functional Foods, vol. 14, pp. 634-640, 2015.

[39] K. Ried and P. Fakler, "Potential of garlic (Allium sativum) in lowering high blood pressure: mechanisms of action and clinical relevance," Integrated Blood Pressure Control, vol. 7, pp. 71-82, 2014.

[40] G. A. Benavides, G. L. Squadrito, R. W. Mills et al., "Hydrogen sulfide mediates the vasoactivity of garlic," Proceedings of the National Academy of Sciences of the United States of America, vol. 104, no. 46, pp. 17977-17982, 2007.

[41] M. H. Traka, A. Melchini, and R. F. Mithen, "Sulforaphane and prostate cancer interception," Drug Discovery Today, vol. 19, no. 9, pp. 1488-1492, 2014.

[42] A. Melchini, M. H. Traka, S. Catania et al., "Antiproliferative activity of the dietary isothiocyanate erucin, a bioactive compound from cruciferous vegetables, on human prostate cancer cells," Nutrition and Cancer, vol. 65, no. 1, pp. 132-138, 2013.

[43] F. Duan, Y. Li, L. Chen et al., "Sulfur inhibits the growth of androgen-independent prostate cancer in vivo," Oncology Letters, vol. 9, no. 1, pp. 437-441, 2015.
[44] R. Z. Amirov, V. T. Karpukhin, and N. I. Nesterov, "Changes in the state of the blood supply to the prostate gland in patients with chronic prostatitis under the influence of treatment with hydrogen sulfide water (according to rheovasographic findings)," Voprosy Kurortologii, Fizioterapii, i Lechebnoi Fizicheskoi Kultury, no. 1, pp. 69-72, 1976.

[45] N. S. Nagaraj, K. R. Anilakumar, and O. V. Singh, "Diallyl disulfide causes caspase-dependent apoptosis in human cancer cells through a Bax-triggered mitochondrial pathway," Journal of Nutritional Biochemistry, vol. 21, no. 5, pp. 405-412, 2010.

[46] D. Y. Shin, G.-Y. Kim, J.-I. Kim et al., "Anti-invasive activity of diallyl disulfide through tightening of tight junctions and inhibition of matrix metalloproteinase activities in LNCaP prostate cancer cells," Toxicology in Vitro, vol. 24, no. 6, pp. 15691576, 2010.

[47] A. Arunkumar, M. R. Vijayababu, N. Srinivasan, M. M. Aruldhas, and J. Arunakaran, "Garlic compound, fiallyl disulfide induces cell cycle arrest in prostate cancer cell line PC-3," Molecular and Cellular Biochemistry, vol. 288, no. 1, pp. 107-113, 2006.

[48] A. Arunkumar, M. R. Vijayababu, N. Gunadharini, G. Krishnamoorthy, and J. Arunakaran, "Induction of apoptosis and histone hyperacetylation by diallyl disulfide in prostate cancer cell line PC-3," Cancer Letters, vol. 251, no. 1, pp. 59-67, 2007.

[49] A. Arunkumar, M. R. Vijayababu, P. Venkataraman, K. Senthilkumar, and J. Arunakaran, "Chemoprevention of rat prostate carcinogenesis by diallyl disulfide, an organosulfur compound of garlic," Biological and Pharmaceutical Bulletin, vol. 29, no. 2, pp. 375-379, 2006.

[50] M. Chen, B. Li, X. Zhao et al., "Effect of diallyl trisulfide derivatives on the induction of apoptosis in human prostate cancer PC-3 cells," Molecular and Cellular Biochemistry, vol. 363, no. 1-2, pp. 75-84, 2012.

[51] D. N. Gunadharini, A. Arunkumar, G. Krishnamoorthy et al., "Antiproliferative effect of diallyl disulfide (DADS) on prostate cancer cell line LNCaP," Cell Biochemistry and Function, vol. 24, no. 5, pp. 407-412, 2006.

[52] R. Arunkumar, G. Sharmila, P. Elumalai et al., "Effect of diallyl disulfide on insulin-like growth factor signaling molecules involved in cell survival and proliferation of human prostate cancer cells in vitro and in silico approach through docking analysis," Phytomedicine, vol. 19, no. 10, pp. 912-923, 2012.

[53] R. Gayathri, D. N. Gunadharini, A. Arunkumar et al., "Effects of diallyl disulfide (DADS) on expression of apoptosis associated proteins in androgen independent human prostate cancer cells (PC-3)," Molecular and Cellular Biochemistry, vol. 320, no. 1-2, pp. 197-203, 2009.

[54] A. Borkowska, N. Knap, and J. Antosiewicz, "Diallyl trisulfide is more cytotoxic to prostate cancer cells PC-3 than to noncancerous epithelial cell line PNT1A: a possible role of p66Shc signaling axis," Nutrition and Cancer, vol. 65, no. 5, pp. 711-717, 2013.

[55] A. Borkowska, A. Sielicka-Dudzin, A. Herman-Antosiewicz et al., "Diallyl trisulfide-induced prostate cancer cell death is associated with Akt/PKB dephosphorylation mediated by Pp66shc," European Journal of Nutrition, vol. 51, no. 7, pp. 817$825,2012$.

[56] D. Xiao, S. Choi, D. E. Johnson et al., "Diallyl trisulfideinduced apoptosis in human prostate cancer cells involves c-Jun $\mathrm{N}$-terminal kinase and extracellular-signal regulated kinasemediated phosphorylation of Bcl-2," Oncogene, vol. 23, no. 33, pp. 5594-5606, 2004. 
[57] D. Xiao, A. Herman-Antosiewicz, J. Antosiewicz et al., "Diallyl trisulfide-induced $\mathrm{G}_{2}-\mathrm{M}$ phase cell cycle arrest in human prostate cancer cells is caused by reactive oxygen speciesdependent destruction and hyperphosphorylation of Cdc25C," Oncogene, vol. 24, no. 41, pp. 6256-6268, 2005.

[58] J. Antosiewicz, A. Herman-Antosiewicz, S. W. Marynowski, and S. V. Singh, "c-Jun $\mathrm{NH}_{2}$-terminal kinase signaling axis regulates diallyl trisulfide-induced generation of reactive oxygen species and cell cycle arrest in human prostate cancer cells," Cancer Research, vol. 66, no. 10, pp. 5379-5386, 2006.

[59] Y.-A. Kim, D. Xiao, H. Xiao et al., "Mitochondria-mediated apoptosis by diallyl trisulfide in human prostate cancer cells is associated with generation of reactive oxygen species and regulated by Bax/Bak," Molecular Cancer Therapeutics, vol. 6, no. 5, pp. 1599-1609, 2007.

[60] A. Sielicka-Dudzin, A. Borkowska, A. Herman-Antosiewicz et al., "Impact of JNK1, JNK2, and ligase Itch on reactive oxygen species formation and survival of prostate cancer cells treated with diallyl trisulfide," European Journal of Nutrition, vol. 51, no. 5, pp. 573-581, 2012.

[61] A. Herman-Antosiewicz, Y.-A. Kim, S.-H. Kim, D. Xiao, and S. V. Singh, "Diallyl trisulfide-induced G2/M phase cell cycle arrest in DU145 cells is associated with delayed nuclear translocation of cyclin-dependent kinase 1," Pharmaceutical Research, vol. 27, no. 6, pp. 1072-1079, 2010.

[62] W.-C. Chen, S.-S. Hsu, C.-T. Chou et al., "Effect of diallyl disulfide on $\mathrm{Ca}^{2+}$ movement and viability in PC3 human prostate cancer cells," Toxicology in Vitro, vol. 25, no. 3, pp. 636643, 2011.

[63] S. V. Singh, A. A. Powolny, S. D. Stan et al., "Garlic constituent diallyl trisulfide prevents development of poorly differentiated prostate cancer and pulmonary metastasis multiplicity in TRAMP mice," Cancer Research, vol. 68, no. 22, pp. 9503-9511, 2008.

[64] D. Xiao, K. L. Lew, Y.-A. Kim et al., "Diallyl trisulfide suppresses growth of PC-3 human prostate cancer xenograft in vivo in association with Bax and Bak induction," Clinical Cancer Research, vol. 12, no. 22, pp. 6836-6843, 2006.

[65] S. Shankar, Q. Chen, S. Ganapathy, K. P. Singh, and R. K. Srivastava, "Diallyl trisulfide increases the effectiveness of TRAIL and inhibits prostate cancer growth in an orthotopic model: molecular mechanisms," Molecular Cancer Therapeutics, vol. 7, no. 8, pp. 2328-2338, 2008.

[66] S. V. Singh, R. Warin, D. Xiao et al., "Sulforaphane inhibits prostate carcinogenesis and pulmonary metastasis in TRAMP mice in association with increased cytotoxicity of natural killer cells," Cancer Research, vol. 69, no. 5, pp. 2117-2125, 2009.

[67] J. W. Chiao, F.-L. Chung, R. Kancherla, T. Ahmed, A. Mittelman, and C. C. Conaway, "Sulforaphane and its metabolite mediate growth arrest and apoptosis in human prostate cancer cells," International journal of oncology, vol. 20, no. 3, pp. 631-636, 2002.

[68] J. J. Alumkal, R. Slottke, J. Schwartzman et al., "A phase II study of sulforaphane-rich broccoli sprout extracts in men with recurrent prostate cancer," Investigational New Drugs, vol. 33, pp. 480-489, 2015.

[69] A. Prudova, M. Albin, Z. Bauman, A. Lin, V. Vitvitsky, and R. Banerjee, "Testosterone regulation of homocysteine metabolism modulates redox status in human prostate cancer cells," Antioxidants and Redox Signaling, vol. 9, no. 11, pp. 18751881, 2007.
[70] S. D. Stan and S. V. Singh, "Transcriptional repression and inhibition of nuclear translocation of androgen receptor by diallyl trisulfide in human prostate cancer cells," Clinical Cancer Research, vol. 15, no. 15, pp. 4895-4903, 2009.

[71] A. Gibbs, J. Schwartzman, V. Deng, and J. Alumkal, "Sulforaphane destabilizes the androgen receptor in prostate cancer cells by inactivating histone deacetylase 6," Proceedings of the National Academy of Sciences of the United States of America, vol. 106, no. 39, pp. 16663-16668, 2009.

[72] M. C. Myzak, K. Hardin, R. Wang, R. H. Dashwood, and E. Ho, "Sulforaphane inhibits histone deacetylase activity in BPH1, LnCaP and PC-3 prostate epithelial cells," Carcinogenesis, vol. 27, no. 4, pp. 811-819, 2006. 


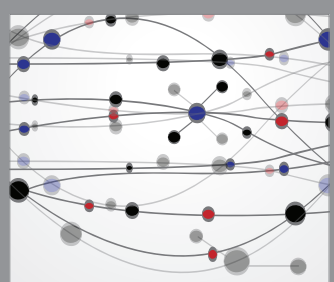

The Scientific World Journal
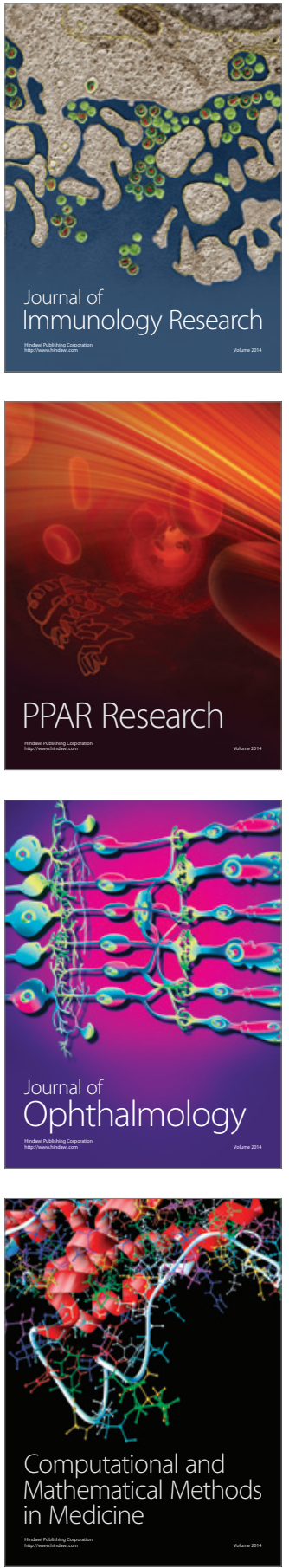

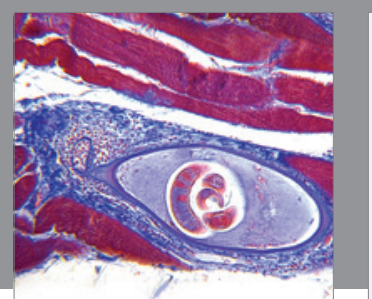

Gastroenterology Research and Practice

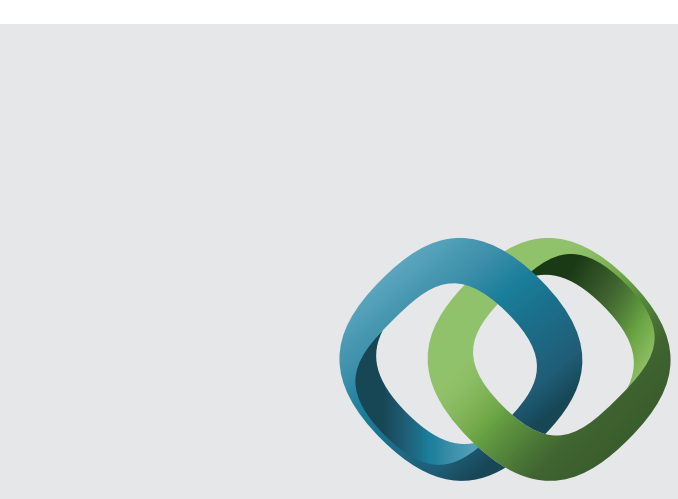

\section{Hindawi}

Submit your manuscripts at

http://www.hindawi.com
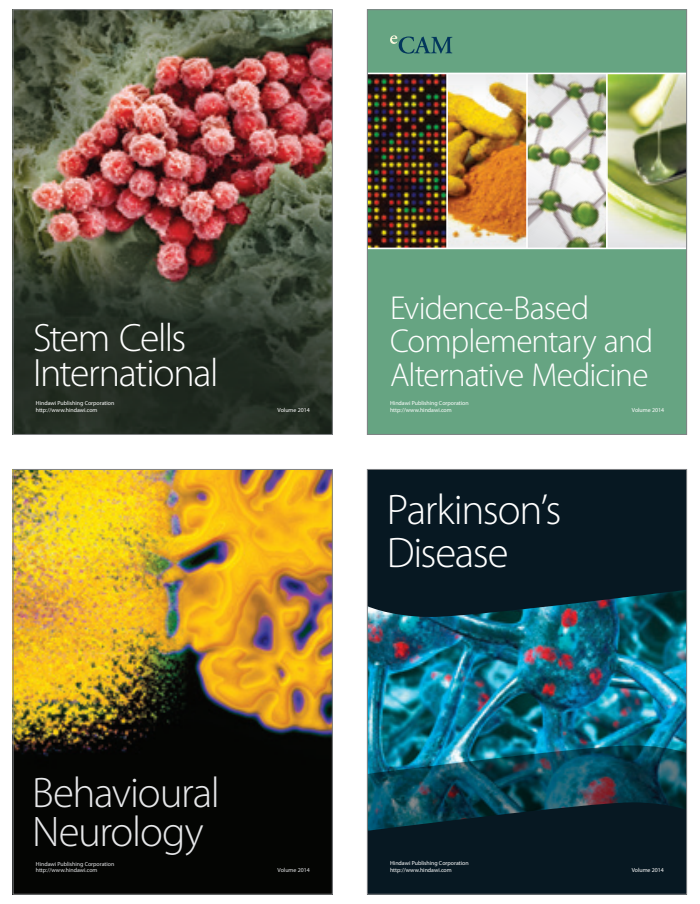
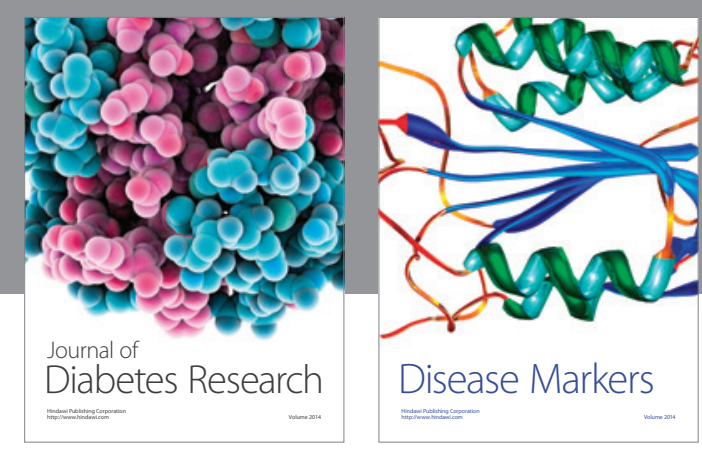

Disease Markers
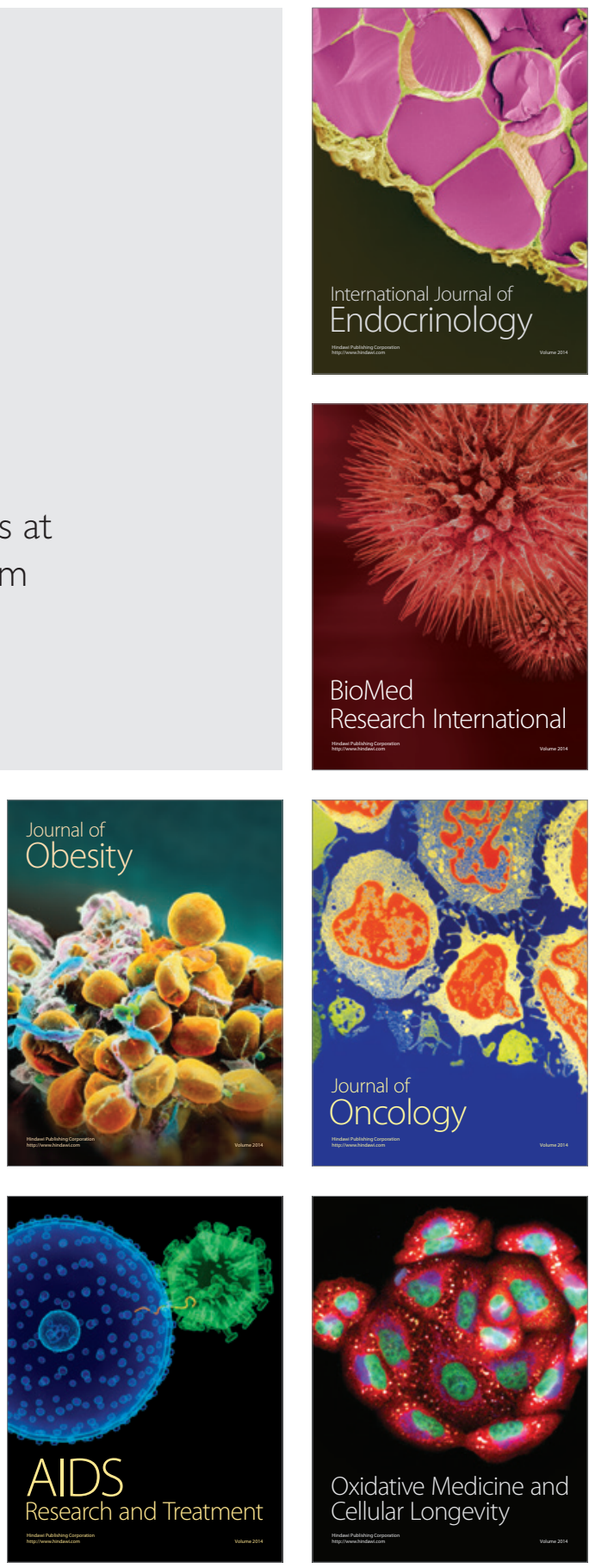